Article

\title{
Evaluating the Relationship between Fruit and Vegetable Growers Use of Plastic Biodegradable Mulches, and Environmental Stewardship and Labor Savings: The Case of Tennessee Fruit and Vegetable Farmers
}

\author{
Margarita Velandia ${ }^{1, *}$, Roderick Rejesus ${ }^{2}$, Christopher Clark ${ }^{1}$, Karen L. DeLong ${ }^{1}$, \\ Annette Wszelaki ${ }^{3}$, Susan Schexnayder ${ }^{4}$ and Kimberly Jensen ${ }^{1}$ \\ 1 Department of Agricultural \& Resource Economics, University of Tennessee, 2621 Morgan cir. Morgan Hall, \\ Knoxville, TN 37996, USA; cclark3@utk.edu (C.C.); kdelong39@utk.edu (K.L.D.); kjensen@utk.edu (K.J.) \\ 2 Department of Agricultural and Resource Economics, North Carolina State University, 2801 Founders Drive, \\ Nelson Hall 4340, Raleigh, NC 27695, USA; rmrejesu@ncsu.edu \\ 3 Department of Plant Sciences, University of Tennessee, 2505 EJ Chapman dr., 112 Plant Biotech Building, \\ Knoxville, TN 37996, USA; awszelak@utk.edu \\ 4 Department of Forestry, Wildlife, and Fisheries, University of Tennessee, 2431 Joe Johnson Dr., 274 Ellington \\ Plant Sciences Building, Knoxville, TN 37996, USA; schexnayder@utk.edu \\ * Correspondence: mvelandia@utk.edu; Tel.: +1-865-974-7409
}

Received: 1 January 2020; Accepted: 6 March 2020; Published: 8 March 2020

\begin{abstract}
The substitution of polyethylene (PE) mulch for plastic biodegradable mulches (BDMs) in fruit and vegetable production has the potential to reduce the negative environmental impacts associated with PE mulch use, and the overall sustainability of fruit and vegetable production. A better understanding of the factors associated with BDM use could inform efforts to promote the use of BDMs. The main goal of this study is to assess the correlation between the use of BDMs among fruit and vegetable farmers, and labor savings and environmental stewardship. Using data from a Tennessee fruit and vegetable farmer survey and probit regressions, this study evaluates the correlation between the use of BDMs, and the labor savings associated with the use of BDMs and farmer environmental stewardship, after controlling for farmer and farmer business characteristics. Results suggest that farm size, farmer environmental stewardship, and labor savings from BDM use are strongly correlated with the use of BDMs among Tennessee fruit and vegetable growers, specifically among those farmers who are more likely to have previous experience using PE mulch.
\end{abstract}

Keywords: plastic biodegradable mulches; Tennessee producer survey; probit regressions

\section{Introduction}

Polyethylene (PE) mulch is widely used by fruit and vegetable farmers because of the multiple benefits it provides, including weed control, soil temperature and moisture conservation, minimization of nutrient loss, and crop yield and quality improvements [1,2]. Fessenden [3] estimates that US agriculture uses approximately one billion pounds of PE mulch per year.

However, there are concerns about the negative environmental impacts of PE mulch. PE mulch is poorly degradable and difficult to recycle [4]. Thus, after being removed, it is typically either taken to a landfill, stockpiled on the farm, tilled into the soil, or burned on site [2]. Additionally, when PE mulch is exposed to light and weathering, it becomes brittle, and is, therefore, difficult to completely remove from fields [5]. Thus, fragments of PE mulch often remain after the majority of the mulch is 
removed. The accumulation of these fragment residues over time results in soil plastic pollution [6]. Soil plastic pollution associated with the use of PE mulch could reduce infiltration, harm biota, and negatively impact crop root development, ultimately reducing productivity and farm profitability [7].

There are other mulch options that provide the same benefits as PE mulch and are proven to have similar performance but pose less of an environmental concern [8-10]. For example, plastic biodegradable mulches (BDMs) do not have to be removed at the end of the season, but rather, are tilled into the soil or composted [11]. Although BDMs are also expected to fragment into smaller microplastics as part of the biodegradation process, these mulches are designed to be decomposed by soil microbes into water, carbon dioxide, and microbial biomass [5]. Therefore, the use of BDMs has the potential to reduce soil plastic pollution caused by the use of PE mulch [7]. Furthermore, because BDMs do not have to be removed at the end of the season, there are labor savings associated with the reduction or elimination of PE mulch removal and disposal activities [12].

There are challenges producers could face when using BDMs depending on the crops they are growing and the environmental conditions they face when growing these crops $[9,12]$. For example, Ghimire et al. [9] and Velandia, Wszelaki, and Galinato [12] suggest that mulch adhesion is a problem that producers could face when using BDMs on crops that could come in contact with the mulch during the cropping season. Nonetheless, as suggested by Velandia, Wszelaki, and Galinato [12], the impact of mulch adhesion on the profitability of BDM use is uncertain and, therefore, needs to be further investigated. Previous studies evaluating the use of BDM among fruit and vegetable growers have not reported mulch adhesion as a barrier to the adoption of BDM [11]. Regardless of the unique benefits and challenges a farm could experience when using BDMs, previous studies suggest that the price of $\mathrm{BDM}$ and the potential labor savings associated with the use of BDM compared to the cost of BDM are the main factors affecting the profitability of BDM use at the farm level [11,12], and potentially farmers' decision to use BDMs.

The substitution of PE mulch for BDM has the potential to reduce the negative environmental impacts associated with PE mulch use, and the overall sustainability of fruit and vegetable production. A better understanding of the factors associated with BDM use, including labor savings and the perception of long-term environmental benefits relative to PE mulch, could inform efforts to promote the use of BDMs, including policy designed to incentivize such use.

Currently, there is little information about the association between labor savings, environmental stewardship and the use of BDMs. One study [11] has explored the perceived bridges and barriers to BDM adoption. Using a qualitative approach, Goldberger et al. [11] identified insufficient knowledge about BDMs, high cost, and unpredictable breakdown as potential barriers to adoption. In contrast, the potential to reduce waste, perceived environmental benefits, and interest in additional information on BDMs were identified as major bridges to adoption [11]. Another studied how perceptions of BDMs influenced the likelihood of using BDMs in the future among strawberry growers in California, the U.S. Pacific Northwest, and the Mid-Atlantic regions [13]. Goldberger, DeVetter, and Dentzman [13] found that availability of BDMs locally, proof that BDMs are not harmful to soil health, and affordability are factors that influence the intention to use BDMs in the future. Velandia, Wszelaki, and Galinato [12] explored the factors affecting the profitability of BDM use in pumpkin production by using field trial data, and a partial budget and sensitivity analyses. Although this study [12] evaluates several hypothetical scenarios to assess factors that could affect net changes in profits when transitioning from PE mulch to BDM in pumpkin production, it does not evaluate the correlation of these factors with pumpkin producers' decisions to use BDMs. Finally, Scaringelly et al. [14] evaluated attitudes towards the use of biodegradable mulches made out of organic wastes among farmers in the Apulia region in Italy. This last study focuses on the willingness to use and willingness to pay for biodegradable mulches made out of organic wastes, which are not available on the market, rather than on the factors associated with the use of these mulch products [14]. None of these studies evaluate the extent to which the potential labor savings associated with the use of BDMs are likely to be correlated with such use [11-14]. Furthermore, although some of these studies suggest an association between the 
perceived environmental benefits of BDMs and the decision to use them, they do not evaluate whether differences in farmer environmental stewardship can help explain the use of BDMs.

In this study, we use data from a survey of Tennessee fruit and vegetable farmers to assess the use of PE mulch and BDM among these growers. We specifically evaluate correlates with BDM use among Tennessee fruit and vegetable farmers, including, their attitudes toward the environment and, for PE mulch users, the amount of time spent removing and disposing of PE mulch at the end of the growing season, and potential labor savings associated with BDM use.

Given the cross-sectional nature of our survey data, it is important to emphasize that we cannot make "causal statements" about the effects of potential labor savings and environmental stewardship on BDM use. Instead, this study only aims to determine whether labor costs and environmental stewardship are empirically correlated with BDM use, after controlling for other observable factors. This is still important, since no study has shown an empirical, quantitative correlation between these variables and BDM use. The analysis presented here can serve as a precursor to a more comprehensive study that causally identifies factors that affect BDM use.

Information from this study can inform efforts to educate farmers on BDM use and to promote the use of BDMs. Extension personnel can use the results to gauge fruit and vegetable farmer interest in BDMs and identify information gaps that prevent farmers from making more fully-informed decisions about the use of BDMs. Using this information, they can develop educational materials to address these knowledge gaps.

Manufacturers currently selling or developing environmentally sustainable mulch products can use information from this study to evaluate the potential market for their products among Tennessee fruit and vegetable farmers and to target farmers who might be more likely to use BDMs. Finally, the decision for a local input supplier to carry BDMs will depend on their assessment of the potential local market for these products. This decision could have implications for the costs that farmers incur to use BDMs, as there could be a significant shipping cost associated with BDMs ordered directly from a manufacturer or an online input supplier [15].

\section{Materials and Methods}

\subsection{Data}

The data used in this study is from a survey of Tennessee fruit and vegetable farmers. The survey was conducted in accordance with the Declaration of Helsinki [16]. All survey respondents gave their informed consent before completing the survey. The survey instrument was approved by the University of Tennessee Institutional Review Board (IRB) (UTK IRB-18-04718-XM).

The Tennessee Department of Agriculture provided a contact list of fruit and vegetable farmers who participated in 2018 in either of two state programs-one that aims to assist Tennessee farmers in marketing (Pick Tennessee Products) and the other that provides cost share for farm improvements (Tennessee Ag Enhancement Program). This is a comprehensive list of Tennessee fruit and vegetable producers, as the eligibility criteria for both programs only guarantee that applicants operate a farm located in Tennessee, are 18 years old at the time of application, and are growing crops for sale [17,18]. Therefore, this contact list mainly guarantees that we are capturing farms located in Tennessee growing crops for marketing purposes. After removing duplicate e-mail and mail addresses, the contact list included 990 fruit and vegetable farmers.

A mixed-mode survey with Web and paper versions was used to improve response rates and reduce coverage and nonresponse error [19]. The Web version of the survey preceded the paper version to reduce survey costs [20]. An invitation to participate in the Web survey was e-mailed to farmers in the contact list for whom we had an e-mail address on 29 January 2019. Reminder e-mails were sent on 5 February and 12 February 2019. On 20 March 2019, a paper version of the survey was mailed to those individuals for whom we had a mail address and either; (1) we did not have an e-mail address; 
(2) e-mail invitations to participate in the Web survey were returned as invalid; or (3) we did not receive a response to the Web survey.

Reminders and follow-up surveys were sent on 30 March 2019 and 5 April 2019, respectively. From the 990 fruit and vegetable farmers in our initial list, 98 do not farm, 135 have e-mail or mail addresses that were marked as undeliverable, two indicated that they were not fruit and vegetable growers, one was retired from farming, and one was ill and unable to complete the survey. In total, there were 186 completed surveys (i.e., 91 online and 95 mail surveys). The overall survey response rate is $25 \%$ (i.e., $186 / 753$ ).

The survey included questions about years of experience using PE mulch and/or BDM; reasons for not using PE mulch and/or BDM; labor hours associated with the disposal and removal of PE mulch; and questions designed to elicit general farmer and farm business characteristics, such as farmer age, education, and hectares in fruit and vegetable production. Paper and online versions of the survey instrument contained identical questions.

To evaluate the representativeness of the survey sample, we categorized the respondents on the basis of hectares in vegetable production (e.g., between 0.04 and 0.39 hectares, 0.40 to 1.99 hectares, etc.) and compare the resulting distribution to the corresponding farm size distribution for Tennessee from the 2017 Census of Agriculture [21] in Figure 1. The 2017 Census of Agriculture does not report combined acres in fruit and vegetable production; it only separately reports acres in vegetable, fruit and nuts, and berry production. Since the majority of the survey respondents indicated either growing only vegetables or vegetables and fruits and berries, we consider acres in vegetable production a good basis for comparison. The farm size distribution from the survey sample follows closely the farm size distribution of vegetable farms in Tennessee (Figure 1). Nonetheless, it is important to notice that the survey sample tends to overrepresent vegetable farms between 2 and 20 hectares and underrepresent farms between 0.04 and 1.99 hectares. This may be explained by the fact that the survey focuses on the use of PE mulch among fruit and vegetable farms in Tennessee and, therefore, larger farms, that are more likely to use PE mulch, are also more likely to respond to the survey. This bias in our survey data may be associated with the main topic of the survey. Therefore, we should be cautious with the conclusions drawn from the analysis presented in this manuscript, as these results may be more likely to be capturing decision-making processes regarding the use of BDMs among larger Tennessee fruit and vegetable farms with previous PE mulch use experience. Survey data indicates the average hectares in fruit and vegetable production among those respondents with previous experience using PE mulch is higher (5.6 hectares), and statistically significantly different at the $10 \%$ level, than the average hectares in fruit and vegetable production for those producers who indicated that they have never used PE mulch (2 hectares). Smaller farms may use alternative mulch products other than PE mulch that are more suitable for small-scale operations such as straw or landscape fabric [22,23].

Survey respondents are, on average, 57 years old, which is close to the average age of farmers in Tennessee (i.e., 58), according to the 2017 Census of Agriculture [21]. Approximately 60 percent of the survey respondents indicated having a bachelor's degree or more education and having, on average, 4.3 hectares in fruit and vegetable production (Table 1). 
Table 1. Summary statistics for selected variables in the survey sample.

\begin{tabular}{|c|c|c|c|c|c|}
\hline Variable Description & $\mathbf{n}$ & Mean & Std Dev & Min & Max \\
\hline \multicolumn{6}{|c|}{ Mulch Use } \\
\hline $\begin{array}{l}P E \_U S E=1 \text { if farmer has used PE mulch; zero } \\
\text { otherwise }\end{array}$ & 184 & 0.5978 & & 0 & 1 \\
\hline $\begin{array}{l}\text { BDM_USE = } 1 \text { if farmer has used BDM; zero } \\
\text { otherwise }\end{array}$ & 181 & 0.1547 & & 0 & 1 \\
\hline EXP_PE-Years using PE mulch; zero otherwise & 108 & 9.7407 & 9.8866 & 1 & 50 \\
\hline$E X P \_B D M-N u m b e r$ of years using BDM & 31 & 1.4194 & 1.2048 & 0 & 6 \\
\hline $\begin{array}{l}\text { Labor_hours }(h / h a) \text { _Labor hours associated with } \\
\text { removal and disposal of PE mulch in hours per } \\
\text { hectare that would be eliminated if using BDM }\end{array}$ & 101 & 42.6134 & 39.1441 & 0 & 198 \\
\hline \multicolumn{6}{|c|}{ Farmer and Farm Business Characteristics } \\
\hline Age-Age in years & 178 & 56.8539 & 14.5986 & 1 & 60 \\
\hline $\begin{array}{l}\text { BSdegree or higher }=1 \text { if farmer has a bachelor's } \\
\text { degree or higher; zero otherwise }\end{array}$ & 185 & 0.5946 & & 0 & 1 \\
\hline $\begin{array}{l}\text { Farm Size_FEV-Hectares in fruit and vegetable } \\
\text { production }\end{array}$ & 156 & 4.3019 & 13.6608 & 0.0243 & 157 \\
\hline \multicolumn{6}{|c|}{ Environmental Stewardship } \\
\hline $\begin{array}{l}\text { Environmental Stewardship-simple average of the } \\
\text { scores associated with the statements below }\end{array}$ & 177 & 3.1497 & 0.9937 & 1 & 5 \\
\hline $\begin{array}{l}\text { "I only buy products in packages that can be } \\
\text { recycled" }\end{array}$ & 177 & 2.8249 & 1.1169 & 1 & 5 \\
\hline $\begin{array}{l}\text { "I try to convince my family or friends not to buy } \\
\text { environmentally harmful products" }\end{array}$ & 177 & 3.4746 & 1.2204 & 1 & 5 \\
\hline \multicolumn{6}{|c|}{ Risk Attitude } \\
\hline $\begin{array}{l}\text { Risk Attitude-simple average of the scores } \\
\text { associated with the statements below }\end{array}$ & 179 & 2.6257 & 0.9770 & 1 & 5 \\
\hline "I like taking financial risks with my farm business" & 178 & 2.3258 & 1.1377 & 1 & 5 \\
\hline "I accept more risk in my farm than other farmers" & 179 & 2.9218 & 1.0885 & 1 & 5 \\
\hline \multicolumn{6}{|c|}{$\begin{array}{c}\text { Ecoregion-1 if the primary farm is located in the Blue Ridge region; } 2 \text { if it is located in the Ridge and } \\
\text { Valley region; } 3 \text { if it is located in the Southwestern Appalachians region; } 4 \text { if it is located in the Interior } \\
\text { Plateau region; } 5 \text { if it is located in the Southeastern Plains region; and } 6 \text { if it is located in the Mississippi } \\
\text { Valley Loess Plains region }\end{array}$} \\
\hline Blue Ridge & 183 & 0.0328 & & 0 & 1 \\
\hline Ridge and Valley & 183 & 0.3060 & & 0 & 1 \\
\hline Southwestern Appalachians & 183 & 0.0765 & & 0 & 1 \\
\hline Interior Plateau & 183 & 0.4317 & & 0 & 1 \\
\hline Southeastern Plains & 183 & 0.0929 & & 0 & 1 \\
\hline Mississippi Valley Loess Plains & 183 & 0.0601 & & 0 & 1 \\
\hline
\end{tabular}




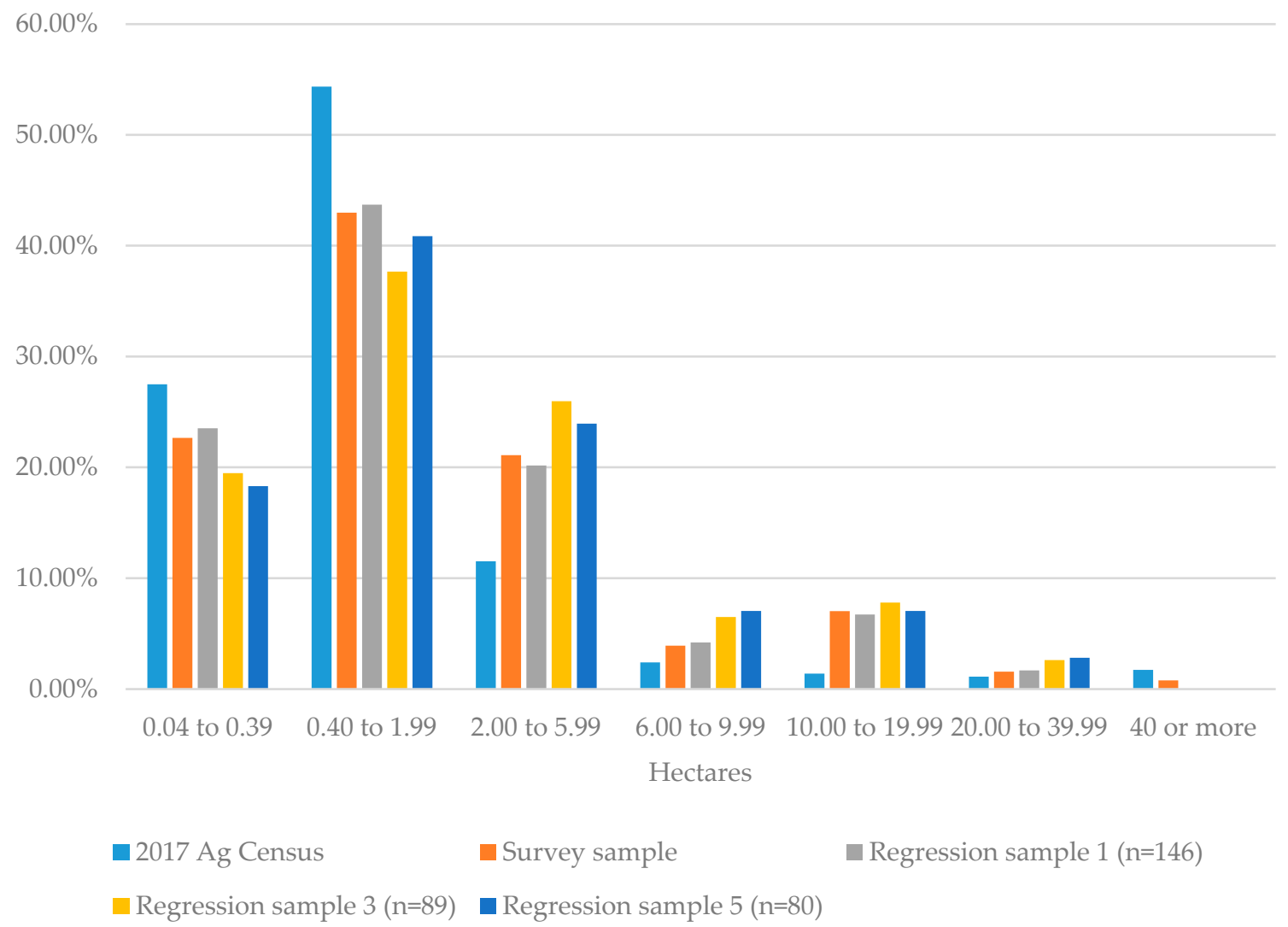

Figure 1. Percentage of farms in each farm size category based on acres in vegetable production according to data from the 2017 U.S. Census of Agriculture, survey sample from the 2019 survey of Tennessee fruit and vegetable farmers about mulch use, and survey subsamples associated with all regression analyses included in this study.

Approximately 60 percent of the survey respondents indicated that they had used PE mulch on their farm, while only approximately 15 percent indicated that they had used BDM (Table 1). Those respondents who had used PE mulches had done so for an average of ten years, while those who had used BDMs had done so for an average of one year and five months.

Respondents estimated that activities related to the removal and disposal of PE mulch took an average of $43 \mathrm{~h}$ per hectare (Table 1 ).

We also asked farmers questions about their behavior as environmental stewards or their responsibility for environmental quality, specifically the one that could be affected by plastic pollution. We tried to capture farmers' responsibility for environmental quality shared by the farmers' actions and the influence they have on their family and friends' actions, specifically, those actions that may be directly or indirectly correlated with plastic pollution. The risk associated with plastic pollution is visible and has received general attention by scientists and the media [24,25], especially plastic pollution in freshwater. Because there is currently no quantification of both probabilities and magnitude related to the risk of plastic pollution in agricultural land, the quantification of risks associated with this type of pollution is uncertain. Therefore, we used statements related to the farmer's and the farmer's family and friends' actions that are indirectly related to overall plastic pollution, such as purchasing products that can be recycled or avoiding to purchase products that are perceived by the farmer as environmentally harmful. Respondents were presented with two statements, one related to their actions "I only buy products in packages that can be recycled", and another one related to their influence on family and friends' actions "I try to convince my family or friend not to buy environmentally harmful products". For each statement, the respondent had to indicate the level of agreement with the statement (e.g., 1 "strongly disagree", 2 "somewhat disagree", 3 "neutral", 
4 "somewhat agree", and 5 "strongly agree") (Table 1). We evaluated the correlation between the scores of these two statements using a Spearman rank correlation coefficient [26]. The estimated Spearman rank correlation coefficient is 0.44 , and the null hypothesis related to the independence between the ranks associated with these statements is rejected at the $1 \%$ significance level. Given that we only have two variables that could help us assess farmer environmental stewardship, we used a similar approach to Chouinard, Wandschneider, and Paterson [27] and created a continuous variable to measure environmental stewardship. Specifically, we used the simple average of the two scores associated with the statements related to farmer environmental stewardship (Environmental Stewardship). The higher the magnitude of this variable, the more likely a farmer is to take actions that are directly or indirectly related to their responsibility with environmental quality, specifically the one that could be affected by plastic pollution.

We also asked farmers questions about their attitudes toward risk. Since previous studies suggest that BDM cost and labor savings are the main factors influencing the profitability of a farm business when adopting BDMs [12], we used statements associated with farmer preferences for financial risks, as an element to be included in a measure of farmer risk preferences. Additionally, since the adoption of a new mulch product is associated with the uncertainty of the performance of the product compared to other mulch products [11], and the fact that the adoption of a new mulch product requires for a farmer to take an additional risk when no farmers have tried or adopted this new product, we also included a variable associated with farmer's acceptance of farm business risk compared to other farmers. Respondents were presented with two statements-one related to their preferences for taking financial risks with their farm businesses "I like taking financial risks with my farm business", and another one related to their willingness to accept risk in their farm compared to other farmers "I accept more risk in my farm than other farmers". Similar to the statements associated with environmental stewardship, for each statement, the respondent had to indicate the level of agreement with the statement (e.g., 1 "strongly agree", 2 "somewhat disagree", 3 "neutral", 4 "somewhat agree", and 5 "strongly agree") (Table 1). We evaluated the correlation between the scores of these two statements using a Spearman rank correlation coefficient [26]. The estimated Spearman rank correlation coefficient is 0.53 , and the null hypothesis related to the independence between the ranks associated with these statements is rejected at the $1 \%$ significance level. Given that we only have two variables that could help us assess farmer risk preferences, we used a similar approach to the one described above for environmental stewardship. We used a continuous variable to measure farmer risk preferences. Specifically, we used the simple average of the two scores associated with the statements related to farmer risk preferences described above (Risk Attitude). The higher the magnitude of this variable, the more likely a farmer is to take risks with their farm business.

\subsection{Empirical Model and Estimation Procedures}

In general, a farmer will adopt BDM if the expected utility of profits of adopting $\operatorname{BDM}\left(E\left[U\left(\pi^{B D M}\right)\right]\right)$ is greater than the expected utility of profits of not adopting BDM $\left(E\left[U\left(\pi^{m}\right)\right]\right)$ or staying with their current mulch option at a certain point in time such that,

$$
E\left[U\left(\pi^{B D M}\right)\right]-E\left[U\left(\pi^{m}\right)\right]>0
$$

where,

$$
\begin{gathered}
E\left[U\left(\pi^{B D M}\right)\right]=E\left[U\left(p f\left(\varepsilon, x_{B D M}, l, x\right)-r_{B D M} x_{B D M}-r_{l} l^{B D M}-r^{\prime} x-d^{B D M}\right)\right] \\
E\left[U\left(\pi^{m}\right)\right]=E\left[U\left(p f\left(\varepsilon, x_{m}, l, x\right)-r_{m} x_{m}-r_{l} l^{m}-r^{\prime} x-d^{m}\right)\right]
\end{gathered}
$$

and, $x$ is a vector of inputs that together with labor $l$ and mulch $x_{m}\left(x_{B D M}\right)$ are used to produce output $q$; output $q$ is a single fruit or vegetable crop (e.g., tomatoes, peppers, strawberries) grown using a particular mulch option; output $q$ is produced through a production function $f($.$) that is assumed$ to be well-behaved (i.e., continuous and twice differentiable); $r$ is a vector of other input prices used 
in the production of $q$, and $l^{m}\left(l^{B D M}\right)$ is labor use when using mulch option $m(\mathrm{BDM}) ; p, r_{m}\left(r_{B D M}\right)$, and $r_{l}$ are output, mulch, and labor prices, respectively; $d^{m}$ and $d^{B D M}$ are vectors of additional costs associated with the use of mulch option $m$ and BDM, respectively. For example, these last vectors could include information about disposal fees associated with the disposal of PE mulch, or the costs of tilling BDMs into the soil. Results presented in Velandia, Wszelaki, and Galinato [12] suggest that when transitioning from PE mulch to BDMs, disposal costs have a small impact on the economic feasibility of adopting BDMs, and machinery costs related to tilling BDM into the soil compared to machinery costs of other end-of-season activities associated with the use of PE mulch could be the same depending on soil and equipment conditions. Therefore, we assume the difference between $d^{m}$ and $d^{B D M}$ is close to zero, at least for those farms transitioning from PE mulch to BDMs. We assume that the farmer faces production risk associated with crop yield variations due to climate conditions that are external to the farmer's actions [28]. Furthermore, the performance of the various mulch options in terms of crop yield and quality improvements is also affected by those climate conditions [9]. The production risk associated with climate conditions is represented by the random variable $\varepsilon$ in (2) and (3).

As explained above, the decision to use BDM requires that the condition presented in equation (1) holds for a particular crop at a specific point in time. We cannot observe the expected utility of profits for each mulch option, but we can observe whether BDM was used or not at some point in time. We do not observe whether the producers adopted and continue using BDM, but rather whether at any point prior to January of 2019, the farmer had used BDM,

$$
Y_{i}^{*}=E\left[U\left(\pi^{B D M}\right)\right]-E\left[U\left(\pi^{m}\right)\right]>0
$$

where, $Y_{i}^{*}$ is an unobservable random index that describes a farmer's propensity to use BDM. The unobservable latent variable $Y_{i}^{*}$ is hypothesized to be a random function of observable exogenous variables included in vector $z$,

$$
Y_{i}^{*}=z_{i}^{\prime} \alpha+e_{i}
$$

Vectors $z_{i}$ of explanatory variables contain information about farmer and farm business characteristics (Table 1) including (1) age measured in years (Age); (2) farmers' education level measured by a dummy variable, taking the value of one if the farmer has a bachelor's or a higher degree (BSdegree or higher); (3) total hectares in fruit and vegetable production (Farm Size FEVV); (4) farm location (Ecoregion); (5) farmer's environmental stewardship or stewardship intentions (Environmental Stewardship); (6) farmer's risk preferences (Risk Attitude); (5) labor hours associated with PE mulch removal and disposal activities (Labor hours); and (6) years of experience using PE mulch (Experience $P E)$ (Table 1). These last two variables are relevant in the decision to use BDMs only for farmers with previous experience using PE mulch. Finally, $\alpha$ is a vector of coefficients associated with the explanatory variables included in $z_{i}$, and $e_{i}$ is a random disturbance term.

Based on the literature focused on factors influencing the adoption of best management practices (BMP) and willingness to use biodegradable mulches made out of organic waste, we expect farmer age and education to be correlated with the use of BDM [14,29,30]. Age is expected to be negatively associated with BDM use as younger farmers, with longer planning horizons, might be more open to new technologies and more likely to be influenced by the potential long-term impacts on the environment associated with the use of PE mulch. On the other hand, farmer educational attainment is expected to be positively correlated with BDM use. It is expected that more educated farmers are more likely to understand complex information about the long-term impacts of other mulch options such as PE mulch on soil health and, therefore, better understand the potential benefits of BDM.

A basic hypothesis considered by previous research is that farm size is correlated with the likelihood of adopting or using sustainable agricultural practices [30,31]. However, D'Souza, Cyphers, and Phipps [29] suggest that, unlike computers and tractors, sustainable agricultural practices do not have a scale effect. For BDM, scale may be relevant because there are labor savings considerations that may be more important for large farms than for small farms. For example, farmers with larger 
farm operations may have to hire workers to complete the removal and disposal of PE mulch because of the scale of their farm. On small farms, the farm owner may be responsible for such removal and, therefore, there may not be a direct cash expense associated with these end-of-season activities, so labor savings associated with the use of BDM may be overlooked [15].

Among producers who have used BDMs, the years of experience using PE mulch is expected to be positively correlated with BDM use. Growers with more experience with PE mulch may be more likely to understand both the benefits and the disadvantages of PE mulch use (e.g., labor and disposal cost, plastic pollution). Therefore, farmers with more years of experience with PE mulch may be more likely to look for alternative mulch options that provide the same benefits of PE mulch but help overcome the challenges associated with the use of these mulches.

Previous studies evaluating the adoption of environmentally sustainable practices, suggest that risk-averse farmers are less likely to adopt these practices [30,31]. Since the variable capturing risk preferences in this study (Risk Attitude) mainly captures farmer risk-seeking behavior, we expect that this variable will be positively associated with the likelihood of using BDM.

Similar to previous studies evaluating the factors correlated with the use of BMP, farmer environmental stewardship (Environmental Stewardship) is expected to be positively correlated with BDM use [30].

We included labor hours associated with PE mulch removal and disposal activities as information farmers with previous experience using PE mulch will incorporate when making the decision to use BDMs. Labor hours associated with PE mulch removal and disposal activities and, therefore, potential labor savings associated with the use of BDM will vary depending on the mulch removal practices used by each farm. After the removal of PE mulch, there are mulch fragments left behind in the field. Not all farmers will make the effort to retrieve these fragments because it is a labor-intensive activity, and they perceive these fragments do not have a negative impact on soil health and long-term productivity [15].

Previous studies evaluating the adoption of agricultural innovations suggest that differences in location characteristics (e.g., land quality, temperature, humidity) are associated with differences in adoption rates [32,33]. For BDM, environmental conditions, specifically those associated with temperature and humidity, will affect the biodegradability of the products and, therefore, the performance of BDM when compared to other mulch options [9,34]. Nonetheless, previous studies suggest that only drastic differences in climate conditions (Tennessee vs. Washington) will have an impact on BDM performance [9]. We control for regional differences in terms of soil and climate conditions across Tennessee (Ecoregions) in the model specifications described below. We used the Environmental Protection Agency (EPA) definition of Tennessee Ecoregions (Figure 2) to capture differences in BDM use based on agroclimatic characteristics (e.g., soil, temperature, precipitations). We specifically used the EPA level III Ecoregions [35].

From Equation (5), the probability of farmer $i$ adopting BDM is given by the following probability model [36]:

$$
\operatorname{Pr}\left[Y_{i}=1\right]=\operatorname{Pr}\left[Y_{i}^{*}>0\right]=\operatorname{Pr}\left[e_{i}<\boldsymbol{z}_{i}^{\prime} \boldsymbol{\alpha}\right]=\Phi\left[e_{i}<\boldsymbol{z}_{i}^{\prime} \boldsymbol{\alpha}\right]
$$

The binary choice model described in Equation (6) is estimated using a probit regression model, assuming that $e_{i}$ is normally distributed with mean zero and standard deviation $\sigma_{e}^{2}\left(N\left(0, \sigma_{e}^{2}\right)\right)$ and that $\Phi($.$) is the cumulative normal distribution [36].$ 


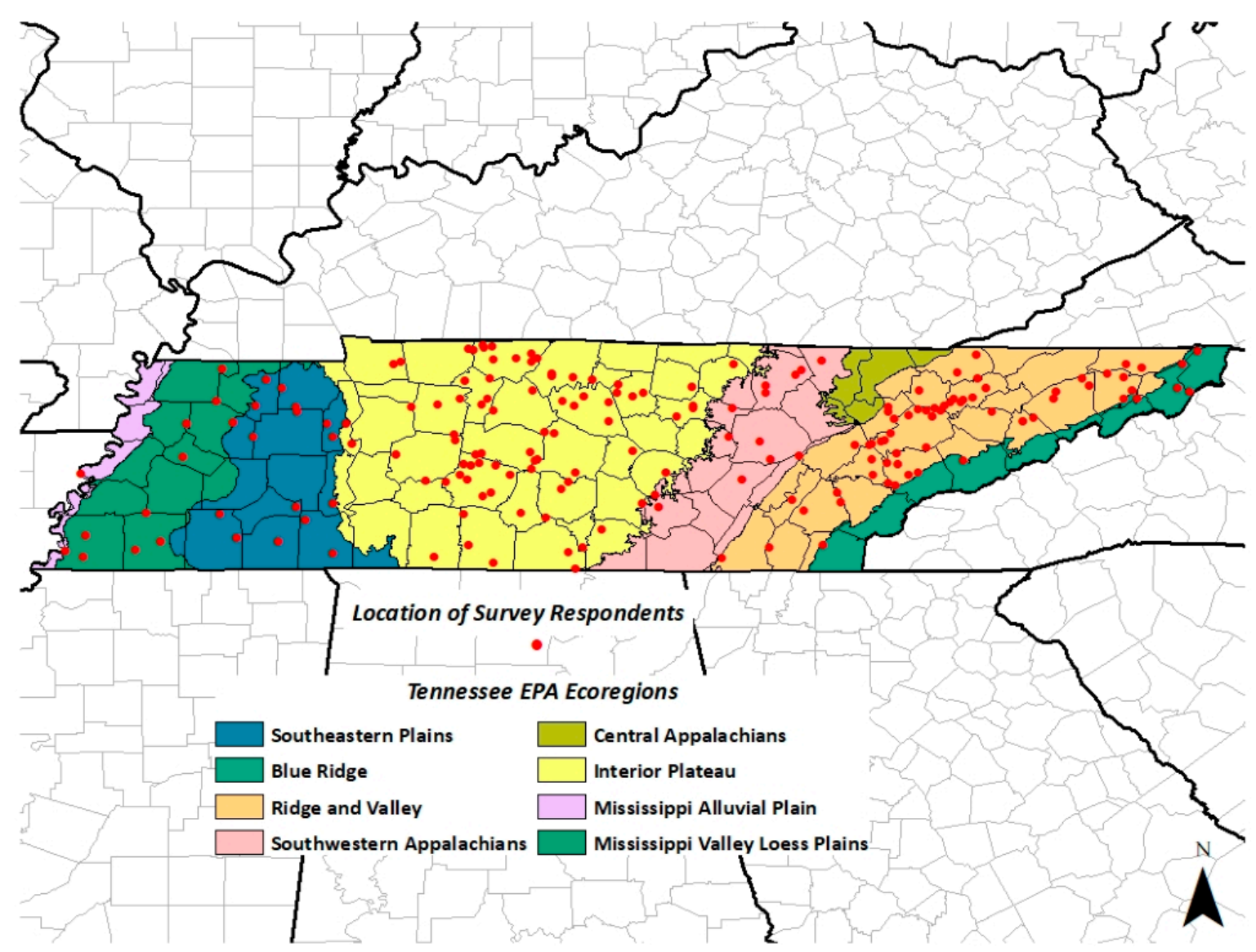

Figure 2. Distribution of respondents across Tennessee ecoregions.

In order to evaluate the association between the probability of adopting BDM and $z$, we estimated the marginal effects associated with these variables. The marginal effects not only allow us to evaluate whether there is a positive or negative association between the independent variables and the probability of adopting BDM, but also the magnitude of this association. The marginal effect for a continuous variable such as Age can be defined as,

$$
\frac{\partial \operatorname{Pr}\left(Y_{i}=1\right)}{\partial z_{\text {age }}}=\phi(.) \alpha_{\text {Age, }}
$$

where, $\phi($.$) is the probability density function for the normal distribution. For discrete variables such$ as BSdegree or higher, the marginal effects can be defined as,

$$
\operatorname{Pr}\left[Y_{i}=1 \mid z_{\text {BSdegree_or_higher }}=1\right]-\operatorname{Pr}\left[Y_{i}=1 \mid z_{\text {BSdegree_or_higher }}=0\right]
$$

As we pointed out in the introduction, and to eliminate any ambiguity, the data and estimation strategy described above do not allow us to make "causal" inferences about the effects of labor savings and environmental stewardship on BDM use. Nonetheless, we are still able to make statements on whether the independent variables of interest are correlated with BDM use. This analysis still provides critical information when assessing the bridges and barriers to BDM adoption.

\subsection{Model Specifications}

We estimate five model specifications to establish the robustness of the findings. The full sample model is estimated to evaluate the factors associated with the use of BDM regardless of other mulch options previously used by the respondent (e.g., PE mulch, straw, no mulch). Previous use of or 
experience with PE mulch is not a necessary condition for considering the use of BDM. Therefore, there are farmers using no mulch or other natural mulch options (e.g., straw) who might also be interested in the benefits of PE mulch but have concerns about the potential negative environmental impact associated with its use and, therefore, consider BDM as the second-best alternative to PE mulch.

An alternative specification of the full sample model is estimated, controlling for differences in agroclimatic conditions. The third and fourth models are estimated to evaluate the factors associated with the use of BDM among PE mulch users only, with and without control of regional agroclimatic differences. Finally, a fifth model is estimated to evaluate the factors associated with BDM use among PE mulch users, after controlling for individual farm removal practices captured by labor hours associated with PE mulch removal and disposal activities, and years of experience using PE mulch.

Since BDM alleviates at least some of the negative environmental impacts associated with the use of PE mulch while providing many of the same benefits as PE mulch, we wanted to compare results from the model that uses the full sample and the model using the subsample of PE mulch users. Additionally, we want to evaluate changes in findings after controlling for differences in mulch removal practices, captured by labor hours associated with these activities (e.g., number of labor hours per hectare associated with removal and disposal of PE mulch) and years of experience using PE mulch among PE mulch users.

Finally, we do not believe that differences in agroclimatic conditions within the state will have any impact on the use of BDM. Nonetheless, we test this hypothesis by comparing the various model specifications with and without controlling for differences in agroclimatic conditions.

\subsection{Diagnostic Tests}

Using a Wald test distributed $\chi^{2}(k)$, we tested the null hypothesis that $H_{O}: \alpha=0$, for the full sample probit regressions and the probit regressions for the subsample of PE mulch users [26]. Rejecting this null hypothesis suggests that at least one of the estimated parameters is different than zero and, therefore, at least one of the independent variables is associated with the probability of adopting BDM.

We used the Akaike Information Criterion (AIC) to identify the regression or model specification that best fits the data. The Akaike Information Criterion (AIC) suggests that the "best" regression model is the one with the lowest AIC or the one minimizing information loss [37].

Inferences can be compromised by inflated variance estimates due to multicollinearity [38]. We use a condition index to detect collinear relationships [38]. Condition indexes between 30 and 100 indicate that the explanatory variables have moderate to strong association with each other. A condition index accompanied by a proportion of variation above 0.5 indicates potential collinearity problems [38].

\section{Results}

Similar to the overall survey sample, the farm size distribution from the subsamples (e.g., samples after deleting missing observations) included in the five estimated probit regressions follows closely the farm size distribution of vegetable farms in Tennessee (Figure 1). It is important to acknowledge that all subsamples tend to overrepresent larger farms that may be more likely to have previous experience with the use of PE mulch. Therefore, the regression analyses presented below may be more likely to capture the association between the variables of interest and the use of BDMs among larger Tennessee fruit and vegetable farms with previous experience using PE mulch. This could affect findings from the full sample model evaluating the factors associated with the use of BDM regardless of other mulch options previously used by the respondents, but not other model specifications that focus on the use of BDM among PE mulch users only. Marginal effect estimates for the five probit regressions, along with the corresponding standard errors, significance levels, and diagnostic test results are presented in Table 2. Results associated with the Wald test distributed $\chi^{2}(k)$ suggest the null hypothesis that all estimated parameters for all probit regression models are equal to zero is rejected and, therefore, at least one of the estimated parameters is different than zero. The Akaike Information Criterion (AIC) 
suggests that the "best" regression models, the ones with the lowest AIC or the ones minimizing information loss [37], are those not including the Ecoregion variable as a regressor. This result may suggest that information regarding location differences within the state of Tennessee is not adding value to the understanding of the factors associated with the use of BDMs. This result is consistent with previous studies suggesting that only drastic differences in climatic conditions (Tennessee vs. Washington) may affect the performance of BDMs [9], and maybe producers' likelihood to use BDMs. Therefore, below, we will only refer to the results associated with the model specifications that do not include Ecoregion as a regressor. Finally, condition indexes associated with the variables included in all probit regressions suggest no evidence of a strong enough association between the explanatory variables included in these regressions that will lead to concerns about multicollinearity.

Table 2. Marginal effects of factors associated with biodegradable mulch (BDM) use.

\begin{tabular}{|c|c|c|c|c|c|}
\hline \multicolumn{6}{|c|}{ Dependent Variable = 1 If Farmer Has Used BDM } \\
\hline & (1) Full sample & $\begin{array}{l}\text { (2) Full sample } \\
\text { Ecoregions }\end{array}$ & (3) PE users & $\begin{array}{l}\text { (4) PE users } \\
\text { Ecoregions }\end{array}$ & $\begin{array}{c}\text { (5) PE users, } \\
\text { controlling for labor } \\
\text { cost and PE experience }\end{array}$ \\
\hline Age & $\begin{array}{c}0.0005 \\
(0.0021)\end{array}$ & $\begin{array}{c}0.0004 \\
(0.0021)\end{array}$ & $\begin{array}{c}0.0009 \\
(0.0033)\end{array}$ & $\begin{array}{c}0.0009 \\
(0.0033)\end{array}$ & $\begin{array}{c}0.0001 \\
(0.0040)\end{array}$ \\
\hline BSdegree or above & $\begin{array}{l}-0.0493 \\
(0.0636)\end{array}$ & $\begin{array}{l}-0.0502 \\
(0.0634)\end{array}$ & $\begin{array}{l}-0.1117 \\
(0.1063)\end{array}$ & $\begin{array}{l}-0.1103 \\
(0.1068)\end{array}$ & $\begin{array}{l}-0.1584 \\
(0.1231)\end{array}$ \\
\hline Farm size FEV & $\begin{array}{c}0.0157^{* * *} \\
(0.0048)\end{array}$ & $\begin{array}{l}0.0155^{* * *} \\
(0.0049)\end{array}$ & $\begin{array}{c}0.0212 * * * \\
(0.0070)\end{array}$ & $\begin{array}{l}0.0207^{* * *} \\
(0.0072)\end{array}$ & $\begin{array}{l}0.0204^{* * *} \\
(0.0074)\end{array}$ \\
\hline Ecoregion & & $\begin{array}{l}-0.0184 \\
(0.0211)\end{array}$ & & $\begin{array}{l}-0.0362 \\
(0.0369)\end{array}$ & \\
\hline Labor hours $(h / h a) / 10$ & & & & & $\begin{array}{c}0.0406^{* * *} \\
(0.0143)\end{array}$ \\
\hline Experience PE & & & & & $\begin{array}{c}0.0109 \\
(0.0070)\end{array}$ \\
\hline Observations & 146 & 146 & 89 & 89 & 80 \\
\hline Wald statistic $\chi^{2}(k)$ & $13.51 * *$ & $14.45^{* *}$ & $12.31 * *$ & $13.06^{* *}$ & $25.88^{* * *}$ \\
\hline
\end{tabular}

Notes: ${ }^{*}, * *$, and ${ }^{* * *}$ represent statistical significance at $10 \%, 5 \%$, and $1 \%$ levels, respectively; AIC, Akaike Information

Criterion; $k$ is the number of regressors included in the regression.

Marginal effects associated with farm size, measured as hectares in fruit and vegetable production, are positive and statistically significant across the five estimated regression models. These results suggest there is a strong association between farm size and the use of BDM, for both all respondents and those who have used PE mulch. Specifically, the results suggest an additional acre in fruit and vegetable production could positively impact the probability of adopting BDM by approximately $2 \%$. For large farm operations looking for mulch options that provide the same benefits than PE mulch, are more environmentally friendly, and have labor savings as an additional benefit, BDM may be the only option. There are other mulch options that may provide similar benefits as PE mulch and are more environmentally friendly (e.g., straw, landscape fabric), but they may be better suited for smaller operations given their management and amount of labor required to use them [22].

For the subsample of PE mulch users, the marginal effects associated with Environmental Stewardship are positive and statistically significant, before and after controlling for mulch removal practices and 
experience with PE mulch. As expected, among PE mulch users, those individuals with a higher tendency to purchase products that have the potential to reduce plastic pollution, such as recycle products, and who encourage others not to purchase environmentally harmful products, maybe more aware about the negative environmental impacts of PE mulch use, and may perceive BDMs as products that reduce these environmental impacts. This result is consistent with previous studies evaluating the adoption of sustainable production practices such as best management practices (BMP) that suggest that farmer's environmental stewardship is positively correlated with the decision to adopt these practices [30]. Additionally, this result is indirectly related to the result presented in Goldberger et al. [11] that suggests that farmers' perceptions about the environmental benefits associated with the use of BDMs are one of the factors that could influence farmers' likelihood of considering the use of BDMs.

For the probit regression that controls for mulch practices and experience with PE mulch, the marginal effect associated with labor hours related to PE mulch removal and disposal (or the potential labor savings associated with transitioning from PE mulch to BDM) is positive and statistically significant. Results suggest that an additional $10 \mathrm{~h}$ spent on PE mulch removal and disposal activities could positively impact the probability of adopting BDMs by approximately $4 \%$. If we multiply the labor hours associated with PE mulch removal and disposal activities by the 2019 Tennessee adverse effect wage rate of $\$ 11.63 / \mathrm{hr}$ [39], this marginal effect implies that a labor costs associated with end-of-season removal and disposal activities of approximately $\$ 116$ per hectare, or potential savings of approximately $\$ 116$ per hectare when transitioning from PE much to BDM could increase the probability of adopting BDM by approximately $4 \%$. This result is consistent with Goldberger et al. [11] assessment of waste reduction as a factor that could positively impact farmers' intentions to use BDMs, specifically waste reduction that reduces labor hours associated with PE mulch end-of-season activities.

According to Velandia, Wszelaki, and Galinato [12], the average price of a 1.2-by-1, $219 \mathrm{~m}$ roll of PE mulch is estimated at $\$ 100$, while the price of a 1.2-by-1, $219 \mathrm{~m}$ roll of BDM is at least $\$ 100$ more expensive than a roll of PE mulch. Therefore, the size of the potential labor savings associated with the use of BDMs (e.g., hours associated with PE mulch removal and disposal activities times the wage rate) could determine the ability to use BDMs and positively impact farm profits [12].

In contrast to findings presented in Scaringelli et al. [14], our results suggest that age and education are not statistically significantly correlated with the use of BDMs. Scaringelli et al. [14] suggest that younger and more educated farmers are more likely to use biodegradable mulch films derived from organic wastes.

\section{Discussion}

The results from this study suggest farmer environmental stewardship and labor savings from $\mathrm{BDM}$ use are strongly correlated with the use of BDMs among Tennessee fruit and vegetable growers, especially among those farmers who are more likely to have previous experience using PE mulches.

One of the important results from this study with direct implications for Extension is the association of labor hours associated with PE mulch removal and disposal and the use of BDM. As suggested by Velandia, Wszelaki, and Galinato [12], labor costs associated with the removal and disposal of PE mulch and, therefore, potential labor savings associated with transitioning from PE mulch to BDM is one of the factors that have the greatest impacts on changes in net profits when making this transition. The results presented in this study support Velandia, Wszelaki, and Galinato [12] findings, as our study suggests that labor hours associated with PE mulch removal and disposal activities and, therefore, potential labor savings when transitioning from PE mulch to BDM are highly correlated with producers' decision to use BDM. Velandia et al. [15] recommend that farmers estimate labor cost of removal and disposal activities to determine whether the potential labor cost savings associated with the use of BDM will offset the higher purchase price of BDM. For small farm operations, the farm owner is often responsible for end-of-season removal and disposal of PE mulch, and, therefore, there is often no out-of-pocket expense associated with these activities. Nonetheless, farmers should keep track of these labor costs to prepare for future scenarios where the farm owner will not be able to perform these 
activities due to illness or physical inability [15]. Extension personnel could help increase awareness of the importance of keeping records of labor cost for end-of-season removal and disposal activities, and the importance of gathering this information before talking to a sales representative about purchasing BDM [15].

Another important result from this study is the suggested positive correlation between farmer environmental stewardship and the use of BDM among PE mulch users. Researchers could use Extension outlets to communicate new findings of the long-term impact of BDM use on soil health, such as the findings presented in Sintim et al. [5], as well as changes in potential government rules regarding the use of BDM in production systems that are considered more environmentally friendly such as organic production systems. For example, in the US, BDMs are not approved for use in organic production systems because none of the BDM products available on the market are completely biobased, a condition imposed by the US Department of Agriculture National Organic Program for the use of these products in organic production systems [40]. This information will help farmers take into consideration the environmental benefits of BDM use to make more informed decisions.

One of the main limitations of this study is that the study findings may be capturing the correlation between labor costs and environmental stewardship and the use of BDMs among larger Tennessee fruit and vegetable farms due to a bias towards larger farms in the survey data. The analysis presented in this study may not be capturing the association between labor hours associated with end-of-season activities, environmental stewardship, and the use of BDMs among small-scale fruit and vegetable farms. For example, for a small farm that has never used PE mulch, the saving associated with the elimination of PE mulch removal and disposal activities will not be associated with the farm operator's decision to use BDMs. If a farmer is using straw or no mulch, there are no removal and disposal activities associated with these mulch alternatives and, therefore, potentially no labor-saving associated with transitioning from these mulch options to BDM. Aside from preferences for more environmentally sustainable mulch products, there may be other factors that could be associated with the use of BDMs among small farms that we are not able to capture in this study. Further research should explore the factors that may be correlated with BDM use among small-scale farms.

Another limitation of this study is that, due to financial constraints, this study is very specific in scope, as it only captures the association between labor hours associated with end-of-season activities, environmental stewardship, and the use of BDMs among Tennessee fruit and vegetable farmers. Future studies should explore the validity of the results presented in this study for other fruit- and vegetable-producing regions in the US and other parts of the world.

Author Contributions: Conceptualization, M.V.; methodology, M.V., R.R., K.J., and K.L.D.; validation, M.V., R.R. and K.L.D.; formal analysis, M.V.; investigation, M.V. and A.W.; resources, M.V., A.W., and S.S.; data curation, S.S. and M.V.; writing — original draft preparation, M.V. and C.C.; writing—review and editing, C.C., A.W., and K.L.D.; visualization, M.V., C.C., and R.R.; supervision, M.V.; project administration, M.V. and S.S. All authors have read and agree to the published version of the manuscript.

Funding: This material is based upon work that is supported by the National Institute of Food and Agriculture, under award number 2014-51181-22382. Any opinions, findings, conclusions, or recommendations expressed in this publication are those of the authors and do not necessarily reflect the view of the U.S. Department of Agriculture.

Acknowledgments: We thank Doug G. Hays for his leadership on acquiring funds and overseeing the research project that supports the research presented in this article.

Conflicts of Interest: The authors declare no conflict of interest and the founding sponsors had no role in the design of the study; in the collection, analyses, or interpretation of data; in the writing of the manuscript, and in the decision to publish the results.

\section{References}

1. Emmert, E.M. Black polyethylene for mulching vegetables. Proc. Am. Soc. Hortic. Sci. 1957, 69, 464-469.

2. Kasirajan, S.; Ngouajio, M. Polyethylene and biodegradable mulches for agricultural applications: A review. Agron. Sustain. Dev. 2012, 32, 501-529. [CrossRef] 
3. Fessenden, M. Most Plastic Trash Comes from Farms. Smithsonina.com. 2015. Available online: https://www.smithsonianmag.com/smart-news/most-plastic-trash-comes-farms-heres-what-were-tryingdo-about-it-180954873/ (accessed on 20 July 2019).

4. Levitan, L.; Barros, A. Recycling Agricultural Plastics in New York State. Environmental Risk Analysis Program; Cornell University: Ithaca, NY, USA, 2003; Available online: http://cwmi.css.cornell.edu/recyclingagplastics. pdf (accessed on 30 July 2019).

5. Sintim, H.Y.; Bandopadhyay, S.; English, M.E.; Bary, A.I.; DeBruyn, J.M.; Schaeffer, S.M.; Miles, C.A.; Reganold, J.P.; Flury, M. Impacts of biodegradable plastic mulches on soil health. Agric. Ecosyst. Environ. 2019, 273, 36-49. [CrossRef]

6. Touchaleaume, F.; Martin-Closas, L.; Angellier-Coussy, H.; Chevillard, A.; Cesar, G.; Gontard, N.; Gastaldi, E. Performance and environmental impact of biodegradable polymers as agricultural mulching films. Chemosphere 2016, 144, 433-439. [CrossRef]

7. Liu, E.K.; He, W.Q.; Yan, C.R. 'White revolution' to 'white pollution'-Agricultural plastic film mulch in China. Environ. Res. Lett. 2014, 9, 091001. [CrossRef]

8. Cowan, J.S.; Miles, C.A.; Andrews, P.K.; Inglis, D.A. Biodegradable mulch performed comparably to polyethylene in high tunnel tomato (Solanum lycopersicum L.) production. J. Sci. Food Agric. 2014, 94, 1854-1864. [CrossRef]

9. Ghimire, S.; Wszelaki, A.L.; Moore, J.C.; Inglis, D.A.; Miles, C.A. Use of biodegradable mulches in pie pumpkin production in two diverse climates. HortScience 2018, 53, 288-294. [CrossRef]

10. Waterer, D. Evaluation of biodegradable mulches for production of warm-season vegetable crops. Can. J. Plant. Sci. 2010, 90, 737-743. [CrossRef]

11. Goldberger, J.; Jones, R.; Miles, C.; Wallace, R.; Inglis, D. Barriers and bridges to the adoption of biodegradable plastic mulches for U.S. specialty crop production. Renew. Agric. Food Syst. 2013, 30, 143-153. [CrossRef]

12. Velandia, M.; Wszelaki, A.; Galinato, S. Economic evaluation of biodegradable plastic in Tennessee pumpkin production. Agronomy 2019, 10, 51. [CrossRef]

13. Goldberger, J.; DeVetter, L.W.; Dentzman, K.E. Polyethylene and biodegradable plastic mulches for strawberry production in the United States: Experiences and opinions of growers in three regions. HortTechnology 2019, 29, 619-628. [CrossRef]

14. Scaringelli, M.A.; Giannoccaro, G.; Prosperi, M.; Lopolito, A. Adoption of biodegradable mulching films in agriculture: Is there a negative prejudice towards materials derived from organic wastes? Ital. J. Agron. 2016, 11, 619-628. [CrossRef]

15. Velandia, M.; Smith, A.; Wszelaki, A.; Galinato, S.; Marsh, T. The Economics of Adopting Biodegradable Plastic Mulch Films; W650; University of Tennessee: Knoxville, TN, USA, 2018; Available online: https: //bit.ly/2OfzOPe (accessed on 20 October 2019).

16. World Medical Association. WMA Declaration of Helsinki-Ethical Principles for Medical Research Involving human subjects. Available online: https://bit.ly/3bCByie (accessed on 15 February 2020).

17. Pick Tennessee Products. Pick Tennessee Products Application. Available online: https://bit.ly/2TduPCS (accessed on 24 February 2020).

18. Tennessee Ag Enhancement Program (TAEP). TAEP Investment Project, 2019 Application B. Available online: https://bit.ly/2T7yt1f (accessed on 24 February 2020).

19. Dillman, D.A.; Smyth, J.D.; Christian, L.M. Internet, Mail, and Mixed-Mode Surveys. The Tailored Design Method; John Wiley \& Sons Inc.: Hoboken, NJ, USA, 2009.

20. McCabe, S.E.; Diez, A.; Boyd, C.J.; Nelson, T.F.; Weitzman, E.R. Comparing web and mail responses in a mixed mode survey in college alcohol use research. Addict. Behav. 2006, 31, 1619-1627. [CrossRef] [PubMed]

21. U.S. Department of Agriculture (USDA), National Agricultural Statistics Service (NASS). 2017 Census of Agriculture. Census Data Query Tool (CDQT). Available online: https://www.nass.usda.gov/Publications/ AgCensus/2017/Online_Resources/Census_Data_Query_Tool/index.php (accessed on 19 August 2019).

22. Schonbeck, M. Mulching for Weed Management in Organic Vegetable Production. eOrganic 4870, eXtension. Available online: https://tinyurl.com/y4qxsl7j (accessed on 26 August 2019).

23. Feldman, R.S.; Holmes, C.E.; Blomgren, T.A. Use of fabric and compost mulches for vegetable production in a low tillage permanent bed system: Effects on crop yield and labor. Am. J. Altern. Agric. 2000, 15, 146-153. [CrossRef] 
24. Gibbens, S. 'Alarming' Level of Microplastics Found in a Major U.S. River. Environment, Planet or Plastic, National Geographi. Available online: https://on.natgeo.com/2SXmUL0 (accessed on 25 February 2020).

25. National Geographic. Planet or Plastic. Available online: https://on.natgeo.com/390CqLM (accessed on 25 February 2020).

26. StataCorp. Base Reference Manual; Statacorp LP: College Station, TX, USA, 2013.

27. Chouinard, H.H.; Wandschneider, P.R.; Paterson, T. Inferences from sparse data: An integrated, meta-utility approach to conservation research. Ecol. Econ. 2016, 122, 71-78. [CrossRef]

28. Koundouri, P.; Nauges, C.; Tzouvelekas, V. Technology adoption under production uncertainty: Theory and application to irrigation technology. Am. J. Agric. Econ. 2006, 88, 658-670. [CrossRef]

29. D'Souza, G.; Cyphers, D.; Phipps, T. Factors affecting the adoption of sustainable agricultural practices. Agric. Resour. Econ. Rev. 1993, 22, 159-165. [CrossRef]

30. Liu, T.; Bruins, R.J.F.; Heberling, M.T. Factors influencing farmers' adoption of best management practices: A review and synthesis. Sustainability 2018, 10, 432. [CrossRef]

31. Fernandez-Cornejo, J.; Beach, E.D.; Huang, W. The adoption of IPM techniques by vegetable growers in Florida, Michigan, and Texas. J. Agric. Appl. Econ. 1994, 26, 158-172. [CrossRef]

32. Mulimbi, W.; Nalley, L.; Dixon, B.; Snell, H.; Huang, Q. Factors influencing adoption of conservation agriculture in the Democratic Republic of the Congo. J. Agric. Appl. Econ. 2019, 51, 622-645. [CrossRef]

33. Feder, G.; Umali, D.L. The adoption of agricultural innovations: A review. Technol. Forecast. Soc. Chang. 1993, 43, 215-239. [CrossRef]

34. Hayes, D.; Wadsworth, L.; Sintim, H.; Flury, M.; English, M.; Schaeffer, S.; Saxton, A. Effect of diverse weathering conditions on the physiochemical properties of biodegradable plastic mulches. Polym. Test. 2017, 62, 454-467. [CrossRef]

35. Environmental Protection Agency. Ecoregion Download Files by State-Region 4. Available online: https://www.epa.gov/eco-research/ecoregion-download-files-state-region-4 (accessed on 27 August 2019).

36. Greene, W.H. Econometric Analysis, 7th ed.; Pearson: New York, NY, USA, 2012.

37. Akaike, H. Information theory as an extension of the maximum likelihood principle. In Second International Symposium on Information Theory; Petrov, B.N., Csaki, F., Eds.; Akademiai Kiado: Budapest, Hungary, 1973; pp. 267-281.

38. Belsley, D.A.; Kuh, E.; Welsch, R.E. Regression Diagnostics: Identifying Influential Data and Sources of Collinearity; John Wiley \& Sons: New York, NY, USA, 1980.

39. U.S. Department of Labor, Employment and Training Administration. Adverse Effect Wage Rates-Year 2019. Available online: https://bit.ly/2Q1xDmg (accessed on 1 August 2019).

40. Ghimire, S.; Hayes, D.; Cowan, J.; Inglis, D.; DeVetter, L.; Miles, C. Biodegradable Plastic mulch and Suitability for Sustainable and Organic Agriculture; FS103E; Washington State University Extension: Mount Vernon, VA, USA, 2018; Available online: https://bit.ly/2SG8M8P (accessed on 19 February 2020). 